SHS Web of Conferences 24, 01008 (2016)

DOI: $10.1051 /$ shsconf/ 20162401008

(C) Owned by the authors, published by EDP Sciences, 2016

\title{
Research on Lahu's traditional sports culture from the perspective of cultural ecology
}

\author{
Youfeng Wang \\ Oxbridge College, Kunming University of Science and Technology, Kunming, Yunnan, China
}

\begin{abstract}
This paper mainly researches Lahu's traditional sports culture from the perspective of cultural ecology and analyzes the characteristics of Lahu's traditional sports culture, and analyzes the characteristics of Lahu's traditional sports culture from three aspects: natural ecological environment, social ecological environment and spiritual ecology. What' more, Lahu' traditional sports culture is not only a concrete expression of Lahu's production form and life style or a symbol of Lahu's religious culture, but also an important embodiment of the nationality, which is an important part in protecting the Lahu nationality. Therefore, this paper also puts forward some suggestions on the inheritance and development of Lahu's traditional sports culture on this basis.
\end{abstract}

Keywords: cultural ecology; Lahu; traditional sports culture

\section{INTRODUCTION}

The traditional ethnic sports activity is a very important cultural phenomenon in the development and evolution of the national society. The traditional sports come from the life and production, and its form is closely associated with the national geographic features. A nation passes through the development in a certain region in a historical period, which gradually forms a particular economic pattern. For example, the agricultural civilization of the Chinese nation and the nomadic civilization of the Northern Mongolian respectively rely on the agricultural economy and nomadic economy, and also respectively forms their own distinctive sports activities, such as Han's spinning top, martial art, dragon boat racing, kite flying and Mongolian horse racing, archery and so on. Lahu has gradually formed its sports activities in the long-term production life, such as pole climbing, archery, canoe walking and Lusheng dance, which has a direct relationship with Lahu's long-term composite economic pattern of farming, hunting and gathering.

\section{LAHU'S TRADITIONAL SPORTS CULTURAL FORM}

(1) Origin and religious belief

Lahu is one of the ancient nationalities in China, orig- inated in the ancient Qiang people in Qinghai, Gansu Province. After the migration to the southern part, it eventually settles alongside Lancang River. Now, it is mainly distributed in Lancang County, Pu'er, Lincang and other places, of which most of them are living in the west of the Lancang River. Lahu has its own language and culture system. Lahu language belongs to Yi language branch with two forms of dialects Lahu $\mathrm{Na}$ and Lahu Xi, without texts. Lahu people have maintained the life style of farming, hunting and gathering for a long time and have formed their own unique religious belief. They believe that everything in nature has a dominate force, "Nei", which exists everywhere, and dominates the sun, the moon, stars, mountains and streams, good or bad weather, good or poor harvest, thus forming a belief system and divination and sacrificial ceremony.

(2) Life style

As for the life style, Lahu people eat cooked or uncooked food. Thus, Lahu nationality has a barbecue tradition. In the language of Lahu, "La" means the tiger and "Hu" means the barbecue. That is, Lahu is a nationality to have barbecue with the tiger meat, which indicates Lahu's feature of braveness and boldness. Besides their staple foods are the bamboo-tube-cooked rice and steamed cake made from the maize meal. In addition, Lahu also remains the production mode of collection. Wild fruits are free of toxicity on mountains, so they can be eaten directly. 
Lahu's housing structure is simple and low-rise. They usually excavate the foundation along the hillside to establish a cob wall and thatched roof. The house is divided into several rooms, which are respectively lived by parents and married children. Each room is set with an independent fireplace, which can dispel dampness.

In ancient times, Lahu people wear robes. In modern times, men wear black collarless jackets and fat trousers; women mainly wear a long turban on head and a long gown with a variety of types, and they also wear typical southern minority's costume. Lahu is not good at spinning technique and their clothing mainly comes from the trade exchange with Hani in the migration period. They start to learn spinning after moving out of the forest to settle in, and then gradually form their own clothing style. They like black as a whole, and most of their clothes are black as a primary color matched with the silver gown, thus forming a sharp contrast between deep and vivid feature with an extreme sense of beauty.

(3) Cultural life

Lahu has many festivals, including the traditional Spring Festival, the Dragon Boat Festival, the Torch Festival, the New Rice Festival, the Gourd Festival and so on, in which the Grabbing New Water and the Dancing Party are the most important. The Grabbing New Water is in the early morning of the first day of the New Year's Day, which is one of the most important festival activities of Lahu. People gather around the mountain spring to grab the new water in the first day of the New Year's Day. When the festival is coming, people of all ages gather together to hold various kinds of celebration activities, which contain a variety of unique traditional sports events, so as to celebrate the festival and activate the atmosphere. Lahu is a nation of monogamy. The youths are allowed to participate in various social activities at the age of fifteen or sixteen. The lovers can be associated by marriage if they fall in love with free premarital social intercourse and without generational restrictions. When the night falls, they sit around the fireplace to sing songs, play jew's harp and Bawu to express love.

\section{ANALYSIS OF CULTURAL ECOLOGY ON TEH CHARACTERISTICS OF LAHU'S TRADITIONAL SPORTS CULTURE}

The cultural ecology is a subject, which is used to research the development characteristics of human cultural groups in a particular geographical environment, and research harmonious relationship between culture and ecology. Culture is inseparable from its historical background and geographical features, and similar ecological environment hastens the formation of similar cultural development vein and form. However, due to a wide gap in the living environment, there is a great difference between the cultural mor- phological characteristics. Therefore, human civilization is able to develop a variety of unique culture.

\subsection{Analysis of natural ecological environment}

\subsubsection{Traditional sports events from production and living skills}

A lot of traditional sports events come from the production and survival needs, especially the minority traditional sports events. The minority produces a variety of sports skill, such as hitting, throwing, shooting, running, and jumping in the process of food acquiring, production and living. Therefore, the traditional sports events can spontaneously reflect the production and life style of the minority, which is also an important part in the minority life.

Lahu nationality has been in a migration state for a long term, whose main production mode is hunting and gathering. Lahu nationality stops migration until the Qing Dynasty and gradually gathers near the Lancang River, then starts to choose farming as the main production mode. However, relying solely on agricultural production is unable to meet the survival needs of Lahu people. Then, they start hunting and gathering again. Therefore, Lahu nationality forms a special production mode of farming, gathering and hunting. Generations of hard life not only hone the will of the Lahu people, but also let the Lahu people have a strong physique. Their production activities are gradually transformed into crossbow, pole climbing, Lusheng dancing and other sports activities, which can also meet the entertainment and survival needs.

\subsubsection{Conditions of geographical climate}

Along the Lancang River, there are high mountains, lofty hills as well as numerous tributaries. The whole county is almost the mountainous and semi- mountainous terrain with rich forest resources, and the forest coverage rate of $31.5 \%$, which is the most dominant geographical climate condition in Lancang County. The abundant forest resources in Lancang County provide the raw materials for Lahu's traditional sports activities. No matter climbing pole, spinning top or shooting cross-bow, the devices are made by the local materials such as bamboo, stone and wood. Lancang County is located in high mountains and lofty hills so that the Lahu ancestors have trained their skills in rock climbing, tree climbing and crossbow shooting in the process of gathering and production. These activities can be completed only under dense jungle conditions. For example, the pole climbing is a summary of the experience in gathering by climbing trees, which gradually develops as a sports event.

Lancang County has a mild climate, abundant rainfall, enough sunshine and adequate resources in the hot zone all year round. Therefore, rice, corn and other food crops are produced in Lancang County. Lahu people maintain a survival mode combined with col- 
lection and farming in a period of time. The traditional sports activities also involve in the item of simulating farming life. For instance, waggle dance is the imitation and artistic processing toward harvesting, fertilizing, planting and other acts during agricultural production. They deeply reflect that the traditional sports activities of Lahu's production and life are dependent on the special natural environment of Lancang County. Without relying on the special geographical environment, it is unable to produce, develop and smoothly implement these seemingly simple traditional sports events.

\subsection{Analysis of social environment ecology}

\subsubsection{Science and technology level}

Science and technology has an important impact on the level of productive forces, which is also a direct driving force of the development of the sports events. The development of the history and modern society has fully proved that this conclusion is correct and scientific. Science and technology is knowledge covering all aspects of the material life, and that also has absorbed the traditional ethnic sports culture. Lahu's traditional sports culture also constantly changes with the progress of the science and technology. The application of more advanced science and technology in the traditional sports activities significantly improves the performance of the traditional competitive sports events, and the upgrading of the communication technology provides a broader show stage for Lahu's traditional sports activities. In addition, publications, television, radio, network and various medium all further the spreading of Lahu's traditional sports culture, thus breaking the limitations of the nation, time and space.

However, continuous improvement of the level of the science and technology also brings new challenges to inheritance and development of the traditional sports culture. With the gradual acceleration of the economic development in ethnic minority regions, the network communication, transportation and other infrastructure construction continue to improve, which brings a lot of changes on Lahu's production and life style. More forms of entertainment are available for people. The size of groups who are interested in the traditional sports events continues to shrink, the large-scale application of the science and technology changes the geographic pattern in ethnic minority regions, and the natural environment relied by the traditional sports culture gradually disappears, resulting in great difficulty in the inheritance and development of Lahu's traditional sports culture.

\subsubsection{Social environment}

Lancang County has a very rapid economic development, whose tertiary industry is the major source of income. It receives a large number of domestic and foreign tourists. The tertiary industry, especially the tourism has the most direct relation with Lahu's traditional sports culture. With the continuous deepening of the reform and opening-up and the market-oriented economic reform, the economic strength of Lancang County continues to strengthen, and the tourism becomes a pillar industry in the county. Lahu is a unique minority in Yunnan, who is also the first batch of indigenous people in Yunnan Province. Therefore, Lahu has rich tourism resources to be developed and a strong attraction to the tourists as well. If Lahu's traditional sports culture can be incorporated into the tourism system of Lancang County as a tourism landscape, it can promote local economic development, achieve profits, and promote the development and innovation of the traditional sports events through creating profits.

For a long time, a race gathering together has become the most common form of social organization. Generally, a village is formed by gathering of several ethnic groups. Lahu also adopts the form of a race gathering together. In Lancang County, there are few habitats available for people to live. Therefore, Lahu forms a lot of villages, thus forming a relatively stable and intimate symbiotic environment, because people in villages know each other with close relations and frequent exchanges between the neighborhoods, so as to facilitate the effective implementation of the traditional sports activities and be capable of forming large-scale group participation. This particular environment of social organization is the human infrastructure of Lahu's traditional sports activities. Nowadays, with the continuous strengthening of China's economic strength, the unprecedented improvement of the urbanization level and the acceleration of the urban construction, more labor forces in the mountainous rural areas are transferred to cities. A significant reduction of Lahu's young and strong laborers makes the traditional sports activities lose the activity objects, thus bringing a serious challenge to the inheritance and development of Lahu's traditional sports culture.

\subsubsection{Values}

With the continuously growing trend of globalization, the Western spirit of the Olympic Games gradually becomes the mainstream of the sports culture, which has a great impact on the inheritance and development of the traditional sports culture of China's minority from the real life and production. With the progress of science and technology, televisions and computers become popular, what's more, NBA, FIFA, beach volleyball, open tennis championship and other western sports events occupy domestic sports market. In addition, in the sports markets in minority areas, ancient myths and the traditional sports that have already lost the actual support of the production and life are unable to attract young people. The impact of the mainstream sports culture on the local traditional sports culture and the transformation of the people's ideas are the core issues in the inheritance and devel- 
opment of Lahu's traditional sports culture.

\section{DEVELOPMENT STRATEGY OF LAHU'S TRADITIONAL SPORTS CULTURE FROM THE PERSPECTIVE OF CULTURAL ECOLOGY}

\subsection{Ecological development of sports culture}

The ecological sports is different from the traditional sports, which is a sports culture system that pursues harmonious coexistence of human-environment-sports, a construction relation and linkage activity of coordination and coexistence and common prosperity of human, environment and sports, and also the sports activity implemented relying on the natural ecological environment and social ecological environment, and the sports culture that stresses the communication with the natural ecology. The ecological sports thought inherits the ancient thought of "man is an integral part of nature", which views dynamic and harmonious development of the man and nature, man and society, man and himself as a main value goal of the sports, and considers that man is an integral part of nature, and man is an expression of natural wisdom. Therefore, the traditional sports culture projects have a strong sense of pursuing the truth and tracing the source. In order to protect and inherit Lahu's traditional sports culture, it is unable to only pay close attention to the sports culture projects. For instance, flowers can be alive with soil through grafting and transplanting. So in order to protect Lahu's traditional sports culture, there is also a need to start from protection of the ecological soil of the sports culture. There is a first need to pay attention to reserving the ecological landscape around Lahu's community, maintaining ecological balance, and there is also a need to comprehensively protect Lahu's traditional cultural ecology, establish and effectively implement the traditional sports courses, and get rid of the vase effect. The traditional sports activity could not be only considered as a single tourism business performance. However, there is a need to actively introduce healthy multi-ethnic sports culture, open up survival soil of the traditional sports culture, establish the traditional sports environment and ease barren and imbalanced traditional sports ecology.

\subsection{Inheritance of the nationality}

Lahu's traditional sports activity has rich historical and cultural stories and myths and legends, which is a manifestation of the national belief in the entertainment life. The national belief is mostly inherited and expressed in the religious form. Most believers look for the significance of life and spiritual sustenance from religion. It is a power source of all life and production activities of a nation, without exception of the sports.

A lot of Lahu's sports activities and folk sports are from the nation's ancestor worship and the worship of God, and gradually developed as the mainstream cultural ideology and nationality cultural self-esteem and identity. For instance, Lahu's waggle dance trusts the belief of "Nei" and prays for their harvest in a new year. The inheritance and memory of the collective belief can significantly promote the inheritance and implementation of these traditional sports activities. And this phenomenon not only exists in Lahu's traditional sports activities. In the Spring Festival of the Zhuang nationality, Maguai Festival is the worship of frog, which prays for good weather for the crops and abundant harvest for all crops in a new year. The traditional martial art is from the "dance", while dance is originally from the witch and sacrifice rites. The common belief on the ancestors and gods has a profound impact on the contemporary Lahu people. By making the best of this point, it is able to effectively mobilize the enthusiasm to hold the traditional sports activities and promote prosperity and development of Lahu's traditional sports culture.

\subsection{Adequate extraction of geography}

Culture is inseparable from the historical background and geographical features. The specific symbol of the national identity is an important symbol of the formation of the national culture, and also a major source of the national cohesion and identity. Lahu nationality adopts the social form of a race gathering in a certain period, and a variety of internal and external contradictions generated in the spontaneous state of its geographical culture require to be regulated by various rituals and cultural customs, and the cultural consciousness is gradually formed in this process. Therefore, Lahu's sports culture forms its own rules, features and perfect belief systems. All of them are not a castle in the air, but a miniature of life of generations of Lahu's people. Lahu's traditional sports culture is an unofficial norm of the traditional values and custom of Lahu people, which is an objective expression of the folk ideology. In the settlement, it is relatively easy for villagers to form the cultural consciousness because of the favorable conditions of the development of Lahu's traditional sports culture. For instance, "waggle dance", "crossbow shooting", "pole climbing" and other physical activities are closely related to Lahu's traditional hunting custom. Lahu nationality is called as a "tiger hunting nation", so the crossbow shooting and similar sports activities are very popular in Lahu. These sports activities with obvious geographical characteristics are symbolic marks of the social identity of Lahu, the sources of the sense of national pride and sense of belonging of Lahu people, and also the power for Lahu people to spontaneously carry out the inheritance and protection of the traditional sports culture and the modernization reform. 
SSHE 2015

\section{CONCLUSION}

Lahu's traditional sports culture is a special form of culture generated by interaction of the local special natural and geographical conditions, production and life style, social structure and science and technology level and a variety of impact elements. The naturally geographical and climatic conditions form a special folk style of Lahu. The inheritance and promotion of its traditional sports culture is a part of minority cultural protection. With the changes of the social and economic forms, natural geographical conditions and the acceleration of urbanization course, it is more difficult to protect and develop Lahu's traditional sports culture. An effective way to solve the reconstruction of the balance of Lahu's traditional sports culture ecosystem is to use the cultural ecology.

\section{REFERENCES}

[1] Zhang Yan, Zhang Jie \& Zhang Shukun. 2015. Analysis of traditional Lahu sports culture from the perspective of cultural ecology. Modern Sports Science, (07).

[2] Duan Qiucen. 2014. Research of Protection of Linear Cultural Heritage Corridor. Yunnan University.
[3] Zhang Min. 2014. Research of cultivation of social responsibility of college students in Kunming by the school's physical education curriculum from the perspective of ecological civilization. Yunnan Normal University.

[4] Bai Shimei. 2013. Changes of traditional sports in Lahu migration of "Lancang River Basin". Yunnan Normal University.

[5] Zhang Zhixian. 2014. Research of integration and development of traditional sports culture of Hani in Red River Valley. Chengdu Sport University.

[6] Liu Jian. 2012. Research of protection and inheritance of traditional sports and intangible cultural heritage of the minority of Yunnan Province. Beijing Sport University.

[7] Zhang Jinfeng. 2013. Research on the ways and measures to improve "soft power" of Yunnan traditional ethnic sports culture. Northwest Normal University.

[8] Guo Liangzhan. 2013. Development and implementation of national folk sports education resources in Shandong Province from the perspective of cultural ecology. Qufu Normal University.

[9] Gao Lei. 2013. Research on bee barrel inspiration in Dananzhi Village of Blang Nationality. Yunnan University.

[10] He Jiaju. 2012. Research on inheritance and development of bamboo bell ball in Tujia. Chengdu Institute of Physical Education. 